(6) OPEN ACCESS

\title{
Diabetes cataract in a 10-year-old girl with new-onset type 1 diabetes mellitus
}

\author{
Jose Bernardo Quintos, ${ }^{01}$ Ana Patricia Torga, ${ }^{2}$ Melissa A Simon ${ }^{3}$
}

\section{'Division of Pediatric}

Endocrinology and Diabetes, Rhode Island Hospital/Hasbro Children's Hospital, The Warren Alpert Medical School of Brown University, Providence, Rhode Island, USA

${ }^{2}$ Division of Pediatric Endocrinology and Diabetes, Rhode Island Hospital/Hasbro Children's Hospital, Providence, Rhode Island, USA

${ }^{3}$ Division of Ophthalmology, The Warren Alpert Medical School of Brown University, Hasbro Children's Hospital, Lifespan Physician Group, Providence, Rhode Island, USA

\section{Correspondence to}

Dr Jose Bernardo Quintos, jbquintos@brown.edu

Accepted 10 January 2019

\section{DESCRIPTION}

A 10-year-old white girl with newly diagnosed type 1 diabetes mellitus (T1DM) presented with progressive deterioration of vision in both eyes within 4 weeks of diagnosis. She had a 3-month history of polyuria, polydipsia, nocturia and generalised hair loss prior to diagnosis. Physical and neurological examination was unremarkable. Baseline ophthalmological examination did not show any diabetic retinopathies. Laboratory findings at presentation include: haemoglobin A1c (HbA1c) of $16.8 \%$ (normal $4.3 \%-5.6 \%$ ), glucose of $763 \mathrm{mg} / \mathrm{dL}$ (normal $60-100 \mathrm{mg} / \mathrm{dL}$ ), bicarbonate of $15 \mathrm{mEq} / \mathrm{L}$ (normal 22-32 mEq/L), anion gap of 24 (normal 3-13) and beta-hydroxybutyrate of $6.22 \mathrm{mmol} / \mathrm{L}$ (normal $0.02-0.27 \mathrm{mmol} / \mathrm{L}$ ). She was started on a basal (glargine) and bolus (lispro) insulin regimen.

Follow-up 1 month after diagnosis showed that her glucose readings were at the target range of $90-150 \mathrm{mg} / \mathrm{dL}$ while receiving a mean daily insulin dose of 1 unit per $\mathrm{kg}$. However, the patient's mother was concerned about her daughter's loss of independence due to a rapid decline in vision. Physical examination showed visual acuity limited to identification of colour and seeing moving shadows

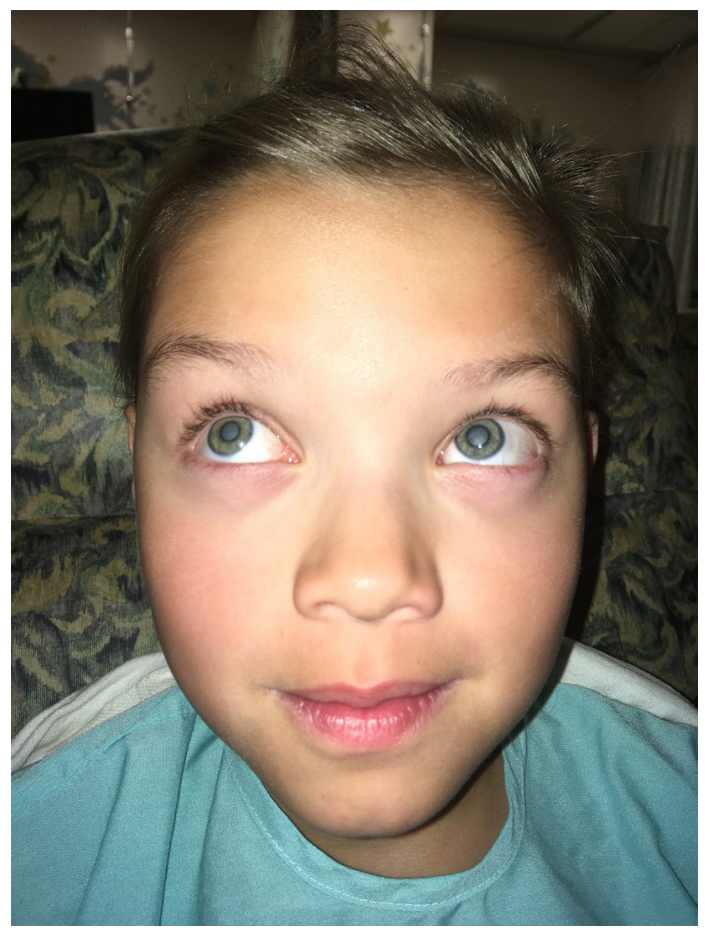

Figure 1 Bilateral eye opacities as seen on physical examination of an adolescent girl with newly diagnosed type 1 diabetes mellitus.

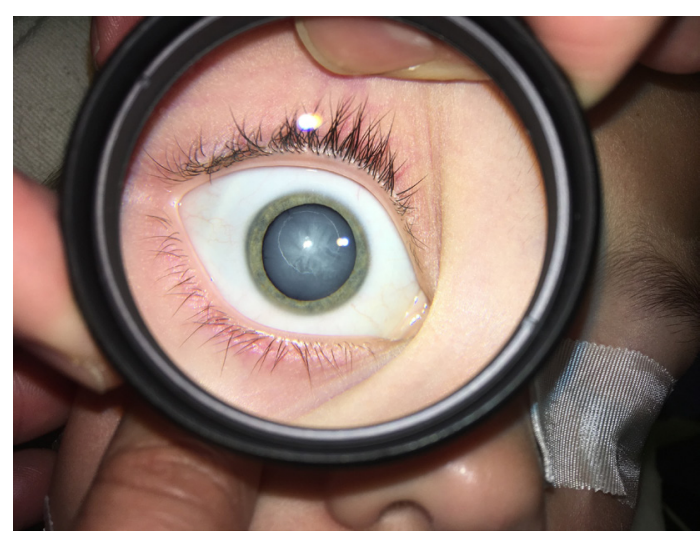

Figure 2 Dilated eye examination of a 10-year-old girl showing dense white cataract of the right eye.

('hand motion' vision) due to lens opacities in both eyes (figure 1). Red reflex with direct ophthalmoscope revealed blunted, whitened reflex bilaterally. The paediatric ophthalmologist confirmed the presence of bilateral dense, white cataracts without peripheral sparing and associated anterior chamber narrowing via dilated slit lamp examination (figure 2).

Cataract is a rare early ocular complication of T1DM in paediatric patients with an estimated prevalence of $0.7 \%-3.4 \%{ }^{1}$ and going up as high as $16 \%$ in patients of Haitian or African descent. ${ }^{2}$ It is mostly seen in adolescent patients with the youngest patient reported at 5 years of age. ${ }^{1}$ Activation of the polyol pathway and acute osmotic stress due to hyperglycaemia are implicated in the opacification of the lens in patients with diabetes. The specific pathophysiological mechanism of cataract formation early in the course of T1DM has yet to be established, however, it has been associated with longer prodromal periods and higher HbA1c (>12\%) on diagnosis. ${ }^{3}$ The morphology of cataracts found in the younger patients with T1DM has been described as scattered opacities in the equatorial region of the lens ('snowstorm cataract') which progress rapidly over the course of weeks or months. ${ }^{4}$

Surgical extraction is the current gold standard in the management of early, visually impairing cataracts in patients with diabetes. There have been isolated reports of regression of metabolic cataracts with good glycaemic control, but there is stronger evidence to support early surgical management, especially among those with poorer visual acuity and when lens opacity obstructs the view of the fundus for examination. ${ }^{1}$ Postoperative complications to watch out for include progression of 
diabetic retinopathy, macular oedema and posterior capsular opacification. $^{4}$

Current guidelines recommend screening for chronic ocular complications starting 3-5 years after diagnosis of T1DM. However, these recommendations largely pertain to diabetic retinopathy and changes in the posterior vasculature of the eye over time. This case showing accelerated development of cataract within weeks from diagnosis is a good reminder to review eye examination in newly diagnosed patients with T1DM especially among those presenting with worsening vision despite improving glucose control.

\section{Learning points}

- Cataract development can occur early in disease course or at the time of diagnosis in patients with type 1 diabetes mellitus (T1DM).

- Cataract should be a differential diagnosis in patients with T1DM presenting with a blurring of vision despite improving glycaemic control.

- Diagnosis in adolescence, and longer prodromal periods prior and higher $\mathrm{HbA} 1 \mathrm{c}(>12 \%)$ prior to diagnosis are risk factors suggesting earlier eye examination among newly diagnosed patients with T1DM.
Contributors JBQ wrote the first draft of the manuscript and edited, with direct care of the patient. APT edited the manuscript. MAS performed data collection, edited manuscript and was involved with direct care of the patient.

Funding The authors have not declared a specific grant for this research from any funding agency in the public, commercial or not-for-profit sectors.

Competing interests None declared.

Patient consent for publication Obtained.

Provenance and peer review Not commissioned; externally peer reviewed.

Open access This is an open access article distributed in accordance with the Creative Commons Attribution Non Commercial (CC BY-NC 4.0) license, which permits others to distribute, remix, adapt, build upon this work non-commercially, and license their derivative works on different terms, provided the original work is properly cited and the use is non-commercial. See: http://creativecommons.org/ licenses/by-nc/4.0/

\section{REFERENCES}

1 Šimunović M, Paradžik M, Škrabić R, et al. Cataract as early ocular complication in children and adolescents with type 1 diabetes mellitus. Int J Endocrinol 2018;2018.

2. Robinson ME, Altenor K, Carpenter C, et al. High rates of ocular complications in a cohort of haitian children and adolescents with diabetes. Yearbook of Paediatric Endocrinology 2018:1124-30

3 lafusco D, Prisco F, Romano MR, et al. Acute juvenile cataract in newly diagnosed type 1 diabetic patients: a description of six cases. Pediatr Diabetes 2011;12:642-8.

4 Pollreisz A, Schmidt-Erfurth U. Diabetic cataract-pathogenesis, epidemiology and treatment. J Ophthalmol 2010;2010:1-8.

Copyright 2019 BMJ Publishing Group. All rights reserved. For permission to reuse any of this content visit https://www.bmj.com/company/products-services/rights-and-licensing/permissions/

BMJ Case Report Fellows may re-use this article for personal use and teaching without any further permission.

Become a Fellow of BMJ Case Reports today and you can:

- Submit as many cases as you like

- Enjoy fast sympathetic peer review and rapid publication of accepted articles

- Access all the published articles

- Re-use any of the published material for personal use and teaching without further permission

For information on Institutional Fellowships contact consortiasales@bmjgroup.com

Visit casereports.bmj.com for more articles like this and to become a Fellow 